\title{
EDUCAÇÃO BÁSICA E FORMAÇÃO PROFISSIONAL NA VISÃO DOS EMPRESÁRIOS BRASILEIROS
}

\author{
Alessandro de Melo*
}

\begin{abstract}
RESUMO: Este artigo pretende contribuir com a área Trabalho e Educação, através da análise descritiva e crítica de um importante documento produzido pela Confederação Nacional da Indústria (CNI) para a Reunião de Presidentes de Organizações Empresariais Ibero-Americanas, realizada no período de 12 a 16 de julho de 1993, em Salvador (BA). Esta análise tem como principal foco o levantamento de questóes acerca da relação dos empresários brasileiros com as demandas para a educação básica, em relação à formação de um trabalhador adaptado às demandas do processo de trabalho caracterizado pela revolução microeletrônica, com habilidades e competências específicas, as quais, a partir dos anos de 1990, passam a ser a bandeira hegemônica do campo pedagógico brasileiro. Nesse sentido, o documento em pauta ganha em relevância pelo seu vanguardismo, adiantando tendências que foram incorporadas à política educacional contemporânea.
\end{abstract}

Palavras-chave: Trabalho e educação. Empresários e educação. Educação básica.

\section{BASIC AND PROFESSIONAL EDUCATION IN THE \\ BRAZILIAN BUSINESSMAN VIEW}

ABSTRACT: This paper contributes to the "Work and Education" area through the descriptive analysis and criticism of an important document produced by the CNI (National Confederation of Industry) for the Meeting of the Ibero-American Business Presidents, held between July 12 and 16, 1993, in Salvador

Mestre em Educação Escolar e professor do Departamento de Pedagogia da Universidade Estadual do Centro-Oeste do Paraná (UnICENTRO).E-mail: alessandrodemelo2006@hotmail.com 
(Bahia, Brazil). Such analysis focuses on the questions raised about the relationship of Brazilian entrepreneurs with the demands for basic education in order to form workers adapted to the needs of the work process characterized by the microelectronics revolution, and endowed with skills and expertise, which, from the early 90 s on, have become the hegemonic banner of the Brazilian educational field. In this sense, such document becomes more relevant because of its vanguardism, since it put forward trends that have been incorporated into the contemporary educational policies.

Key words: Work and education. Businessman and education. Basic education.

\section{Introdução}

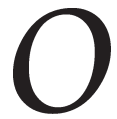

documento Educação Básica e Formação Profissional (EBFP), produzido a partir da $6^{\circ}$ Reunião de Presidentes de Organizaçōes Empresariais Ibero-Americanas, realizada pela Confederação Nacional da Indústria (CNI), no período de 12 a 16 de julho de 1993, em Salvador, é o objeto deste artigo, que pretende discutir detalhadamente os princípios e as proposiçôes educacionais da burguesia industrial brasileira para a educação básica e para a educação profissional.

Este documento é aqui entendido como um dos mais importantes manifestos públicos da burguesia industrial brasileira sobre a educação básica e formação profissional publicado nos anos de 1990. As ideias nele impressas estão presentes até hoje nos documentos da CNI, o que evidencia seu poder de síntese do pensamento desta classe, que desde a década de 1930, tendo a CNI como vanguarda, vem se organizando para conseguir a hegemonia política na sociedade.

Deluiz (1996) percorre as ideias dos empresários e trabalhadores desde os anos de 1980 e meados da década de 1990 e afirma a antecipação dos empresários na consolidação de uma proposta educacional orgânica aos novos tempos do capitalismo, caracterizado pela implementação de uma base microeletrônica na produção e de uma gestão e produção flexível do trabalho (Harvey, 2002). Estas mudanças, já evidenciadas pela CNI em documento de 1988, marcam a entrada do pensamento burguês industrial na corrida pela competitividade em nível mundial da indústria brasileira (CNI, 1988). 
Estas mudanças nos marcos da produção exigem como contrapartida alterações no perfil formativo da classe trabalhadora, que, em poucas palavras, centram-se na flexibilização desta formação, no seu esvaziamento de conteúdos científicos e técnicos mais avançados para a classe trabalhadora, em geral, e, para uma pequena classe, uma alta qualificação para poucos postos de trabalho (Harvey, 2002).

O documento EBFP aparece como norteador desta nova orientação formativa, em especial pela adoção de marcos como a empregabilidade e as três habilidades - básica, específica e de gestão - que completam o perfil do trabalhador adaptado aos tempos de competitividade e de um mercado de trabalho em crise, devido ao desemprego generalizado.

Não se pode esquecer que é no início da década de 1990, após Jontiem, que se iniciou no Brasil e América Latina um movimento de centralização na educação básica e no esvaziamento dos conteúdos formativos, em nome de uma formação genérica, de base psicológica, individualista, encontradas em documentos como os Parâmetros Curriculares Nacionais (PCN), o Relatório Jacques Delors e o Plano Nacional de Qualificação do Trabalhador (PLANFOR), que será aqui especialmente analisado (Duarte, 2000; Silva, 2007; Oliveira, 2003a, 2003b; Ramos, 2001).

Num primeiro momento, será realizada uma abordagem de contextualização do documento EBFP, aproveitando-se do movimento empreendido por Deluiz (1993) e Rodrigues (1998). Em seguida, serão realizadas as análises do documento, parte por parte, mantendo o diálogo com os autores que já o analisaram. A questão do PLANFOR será abordada na penúltima parte, quando serão abordadas as três habilidades constitutivas do perfil profissional requerido pelos empresários. Para terminar a análise do documento EBFP, serão abordadas, com o auxílio de Oliveira (2003b), as proposições da burguesia industrial sobre a participação dos empresários no gerenciamento da educação e dos recursos a ela direcionados.

\section{O fator trabalho}

Para os empresários, os recursos humanos das empresas, como um fator essencial para a competitividade destas, e, portanto, o trabalhador não podem mais ser tratados como uma peça de fácil reposição, que pode ser submetida a um tratamento precário ou simplesmente 
vista como "gasto necessário", aos moldes do taylorismo/fordismo. Esta, portanto, é uma relação que se pode resumir em uma equação simples: qualidade dos recursos humanos e valorização do trabalhador igual à maior competitividade. Rodrigues (1998) acentua que, no discurso empresarial, a produtividade, pela via da melhoria dos recursos humanos, acabará por resolver problemas sociais.

Mais uma característica apresentada no documento EBFP é que esta relação entre capital e trabalho possui uma conotação ideológica centrada na diluição das contradições de classe derivadas do modo de produção capitalista. Isso porque, para o capital, já não vale mais a velha relação de exploração pura e simples dos trabalhadores.

O clássico embate capital/trabalho, base sobre a qual se assentou grande parte das teses educacionais, vê-se agora desafiado por novas e contestadoras posturas, motivadas pelos ventos das atuais condiçôes de desenvolvimento das forças produtivas que, em nossa realidade, embora ocorram de maneira desigual, não podem ser ignoradas. (CNI, 1993, p. 8)

Para os empresários, portanto, as relações entre capital e trabalho, mediadas por uma nova exigência de qualificação e de mudanças gerenciais, que "aproximam" trabalhadores e gestores, já não podem ser mais entendidas como relações contraditórias, de disputa de duas classes opostas, que lutam por ideais e uma sociedade diferente.

Os motivos que levam a burguesia industrial a afirmar a superação da contradição essencial entre capital e trabalho assentam-se sobre os seguintes pilares: a ascensão das subjetividades, o novo modelo de gestão do trabalho e a consequente qualificação e diminuição da distância entre o fazer e o pensar. Quanto ao primeiro, afirma Rodrigues (1998, p. 108):

(...) para a burguesia industrial, a atual produção científica no campo das ciências humano-sociais, fortemente marcada pelos conceitos de subjetividade, gênero, e etnia, acabou por conformar uma compreensão da realidade social radicalmente distinta daquela estabelecida pela economia política marxista. As desigualdades sociais não são expressão da cisão societária produzida, em última instância, pela exploração de uma classe fundamental (a burguesia) sobre a outra (o proletariado). As desigualdades sociais são, sim, produto da subjetividade, das relações de gênero e etnia. 
A análise do projeto educacional da burguesia industrial brasileira não pode ser apartada da sua visão de sociedade, apontada acima. A ênfase na educação básica, na formação de habilidades genéricas para os trabalhadores e a sua inserção como elemento para a competitividade, aos moldes da teoria do capital humano revisada, são partes desta concepção funcionalista de sociedade, em que a desigualdade se transforma em diferenças, em que classes sociais são substituídas pelo acento nas subjetividades. Por este caminho, percebe-se o perfil do trabalhador que se quer formar para os interesses da burguesia industrial: um trabalhador que não se compromete como elemento de classe, mas apenas consigo mesmo e com a empresa.

Por outro lado, há o pilar dos modelos de gestão da produção. Neste caso, o que ocorre é que as mudanças tendem a reduzir os níveis hierárquicos das empresas, entre os que fazem e os que projetam a produção, fazendo o conflito entre capital e trabalho perder o sentido. Não se trata mais de contradições, mas de diferentes funçôes que tendem a se harmonizar para a conquista do grande objetivo: a competitividade da indústria, que fortalece a economia e, por conseguinte, gera empregos e desenvolvimento para a sociedade. Assim, o projeto de uma classe se transforma em projeto de toda a sociedade. Em resumo, afirma Rodrigues (idem, p. 109):

(...) para a burguesia industrial, as novas tecnologias e os novos paradigmas teóricos acabam por destruir as demarcações ético-teórico-políticas postas pelo pensamento marxista, e, consequentemente, socavam todo o pensamento pedagógico que do materialismo histórico-dialético se reivindica.

O projeto educacional da burguesia industrial, de base funcionalista, é contrário, portanto, às teorias marxistas, que reivindicam uma educação transformadora e revolucionária, que supere uma formação meramente instrumental para o mercado de trabalho.

Os empresários criticam também o modelo de Welfare State, que utilizava a educação profissional como política de amenização da pobreza nos anos de 1960 e 1970 e, mais ainda, com a crise dos anos de 1980. Estes valores, como o pleno emprego e "ajuste de treinamento para postos de trabalho predeterminados", são questionados como nãopassíveis de serem saída para a atual forma de competitividade que permeia a relação entre educação e mercado de trabalho. 
Os empresários pedem, na reforma educacional, a universalização da educação básica, até os dezoito anos de idade, com doze de estudos. Exigem também medidas de educação permanente e recorrente.

Já não é possivel que o individuo invista um grande periodo de tempo na educação e na formação profissional, com a intenção de adquirir um fundo de conhecimento ou de qualificação que seja suficiente para toda a sua carreira. A educação recebida pelos jovens deve ter uma base sólida, que facilite constantes aquisiçôes e atualização de conhecimento para o resto de sua vida produtiva. (CNI, 1993, p. 10; itálico do original)

Em primeiro lugar, é necessário apontar a positividade do conteúdo do discurso da burguesia industrial brasileira descrito acima. De fato, como analisou Rodrigues (1998), nem sempre a CNI defendeu a universalização da educação básica no país.

As mudanças no mundo do trabalho exigem que trabalhador se qualifique constantemente e que sua formação básica seja direcionada para esta flexibilidade, que deverá incorporar para alavancar sua carreira. Logo, a proposta dos empresários vincula-se muito mais à aquisição de métodos de aprender do que a conteúdos a serem aprendidos. Segundo Rodrigues (1998, p. 110): "Em outras palavras, nesse documento, os empresários industriais estão propondo uma educação capaz de produzir conhecimentos transitivos e generalizáveis, ou seja, passíveis de continuar a produzir-se, mesmo depois da saída do indivíduo do sistema formal de educação".

No entanto, frente a uma demanda como esta, os empresários verificam que os sistemas educacionais da América Latina nem de longe cumprem este papel de oferecer uma educação básica sólida e, portanto, não estão formando "(...) um trabalhador que seja economicamente produtivo e pleno cidadão" (CNI, 1993, p. 10; destaque do original).

\section{As novas tecnologias e as demandas de formação}

Nesta parte do documento, os empresários demonstram clareza ao assinalarem as características do novo cenário do mundo do trabalho flexibilizado e de como estas mudanças passam a exigir um novo tipo de formação a ser tomada como paradigma para a escola, sobretudo a escola pública brasileira, haja vista a capacidade limitada do 
sistema produtivo de generalizar oferta de educação básica e profissional. Para os empresários:

O novo paradigma da produção industrial tem seu fulcro em uma produção flexível e diversificada, na versatilidade, na modificação de produtos em função das necessidades e interesses do consumidor, bem como em uma organização do trabalho também flexível e descentralizada, com ampla capacidade de reação e adaptação a novas mudanças. Isso significa que a integração com a contemporaneidade do mundo implica em maior desenvolvimento e apropriação da ciência e tecnologia enquanto principais instrumentos da dinâmica do sistema produtivo moderno. (Idem, ibid., p. 13)

Há, portanto, nesta nova demanda uma dupla flexibilização: por um lado, a necessidade de se adaptar internamente à produção, na própria fábrica, que lhe exige cada vez mais habilidades genéricas, como a comunicação e a capacidade de trabalhar em grupos e liderar (Ferretti, 2003); por outro lado, pelo fato de que, de olho no cenário social, em especial o mercado de trabalho, o trabalhador percebe que a sua segurança depende da iniciativa em gerenciar a sua própria carreira.

Visando à competitividade, os empresários percebem que o diferencial são os recursos humanos de que dispõem e, portanto, passam a valorizar os trabalhadores como capital humano. No mais típico vocabulário da teoria do capital humano, os empresários vêem os trabalhadores como "(...) bens a serem incrementados para que se lhes possa adicionar valor, em oposição a custos que devem ser reduzidos" (CNI, 1993, p. 13). Rodrigues (1998), por meio desta colocação, afirma que a valorização dos trabalhadores, de fato, se refere à sua capacidade de produção da mais-valia. E mais, como afirma Oliveira (2003b), a teoria do capital humano, subsídio das propostas educacionais da burguesia industrial, é aquela teoria orgânica aos verdadeiros interesses desta classe, cujo objetivo não é mudar o real. Assim, “(...) só teria sentido apoiar-se em uma 'teoria' que em nada contribui para pensar a educação sobre outras bases que não seja a de reprodução do modelo capitalista de produção” (p. 52).

Para a burguesia industrial, pensando estrategicamente na mãode-obra como capital humano nesta nova fase de acumulação, não se pode mais ignorar as deficiências no sistema de ensino, como era possível no taylorismo/fordismo. A má educação influencia a produtividade, hoje, de forma direta. 
A atual revolução tecnológica, à diferença da primeira revolução industrial, que teve o mérito de substituir a força física do homem pela energia mecânica, caracteriza-se por ampliar a capacidade intelectual humana na produção industrial e nos serviços. (CNI, 1993, p. 14)

Por meio desta declaração, resulta que a exploração do trabalho já não se dá somente pela retirada das forças psicofísicas dos trabalhadores, mas também pela exploração da capacidade intelectual destes na produção, como é o caso da fábrica Toyota, descrita e analisada por Eunice de Oliveira (2004).

Os empresários, no documento EBFP, aparecem na vanguarda com relação às competências necessárias à educação neste período histórico.

Além da modernização quantitativa, é necessário que a escola desempenhe o papel pedagógico de aguçar no estudante a elaboração crítica, a independência e a capacidade de organização do próprio trabalho. Seriam estas, em síntese, as competências básicas a serem priorizadas nos currículos de educação geral e formação profissional. (CNI, 1993, p. 14-15)

Encontram-se nestas três características as bases fundamentais do que se entende por trabalhador flexível e adaptado às demandas da chamada "nova economia", ou seja, em primeiro lugar, é exigida a "crítica", no sentido de que os trabalhadores precisam se apropriar de processos teóricos, abstratos, que estão no cerne das máquinas microeletrônicas. Em segundo lugar, o trabalhador deve ser independente e procurar se colocar, frente ao mercado de trabalho excludente, de forma ativa, dinâmica, enfim, de maneira que possa gerir independentemente a sua própria carreira. Em último lugar, a competência de que o trabalhador deve organizar seu próprio trabalho tende, no sentido mais atual, ao empreendedorismo.

Frente às três competências básicas, os empresários falam de um "novo homem" a ser gerado neste processo. Este "novo homem" que a "necessidade aponta" deve ser o "criador de sua própria história", capaz de agir e escolher "livremente" frente a diversificadas situações e alternativas no mundo do trabalho. Ocorre, neste sentido, uma inversão ontológica, ou seja, o homem, nesta concepção, deixa de ser social por natureza, devido ao fato de que lhe são exigidas capacidades de ação individual, independente dos demais homens, e, neste sentido, tornase individualista. 


\section{A polivalência}

Uma importante categoria que está expressa no documento EBFP é a "polivalência", que reforça a crítica à formação fragmentada típica do modelo fordista/taylorista (Kuenzer, 1985, 2002, 2003).

O posto de trabalho fordista, unificado e parcelado, foi substituído pela flexibilidade, pelas famílias de ocupação, pelas ilhas de produção, em que os trabalhadores são chamados a efetuar diversos tipos de trabalho, a operar diversas máquinas ao mesmo tempo, de gerenciar e se responsabilizar pelo andamento daquela seção de trabalho, sozinho ou em grupo (Kuenzer, 2003; Oliveira, 2004). Dada a importância da polivalência para o projeto educacional dos empresários, vejamos como estes tratam o conceito:

É necessário, portanto, assegurar, por um lado, a universalização e a adequação qualitativa da Educação Geral, e também o caráter científico e educativo da Formação Profissional, através de uma qualificação polivalente, isto é, de uma educação de caráter geral e abrangente que garanta a unidade da teoria com a prática e do concreto com o abstrato.

O conceito de polivalência implica uma formação que qualifique as pessoas para diferentes postos de trabalho dentro de uma família ocupacional e, sobretudo, para complementar as bases gerais, científico-técnicas e socioeconômicas da produção em seu conjunto. Uma formação que articule a aquisiçāo de habilidades e destrezas genéricas e específicas com o desenvolvimento de capacidades intelectuais e estéticas. Implica, portanto, não só a aquisição de possibilidades de pensamento teórico, abstrato, capaz de analisar, de pensar estrategicamente, de planejar e de responder criativamente às situaçôes novas, mas também de capacidades sócio-comunicativas, de modo a poder desenvolver trabalho em equipe e conhecimentos ampliados que possibilitem a independência profissional. (CNI, 1993, p. 16)

Não se pode negar a positividade desta proposição como política de formação dos trabalhadores, pois, contraditoriamente, se os empresários querem esta formação para uma melhor qualificação para a produtividade e competitividade, para os trabalhadores esta formação mais densa de teoria e prática pode vir a ser um mecanismo de luta transformadora.

No entanto, como criticou Oliveira (2003a), o conceito de polivalência é usado ideologicamente pelos empresários, visando à 
conquista da hegemonia política, criando a falsa impressão de que o trabalho contemporâneo exigiria do trabalhador maior qualificação. $\mathrm{Na}$ verdade, afirma o autor, os empresários demandam um trabalhador multifuncional.

As características do trabalhador polivalente reiteram o anteriormente afirmado de que, sob a égide da reestruturação produtiva do trabalho e da gestão flexível do trabalho, a exploração do trabalhador dá um salto de qualidade, no sentido de que esta passa a ocorrer pelo viés de uma pretensa totalidade do ser humano, que exige do trabalhador o máximo desempenho na atribuição de suas funções, não somente no âmbito das disposições psicofísicas, mas também espirituais e intelectuais.

A valorização dos recursos humanos nas empresas exige uma urgente reforma curricular, baseada em três eixos: “(a) flexibilidade no saber; (b) interdisciplinaridade do conhecimento; (c) construção, pelo indivíduo, de uma visão globalizante dos processos tecnológicos, com ênfase na abstração, na apropriação de mecanismos lógicos e na transformação da maneira de pensar e construir conceitos" (CNI, 1993, p. 17).

Pelas três bases da reforma curricular pretendida pelos empresários, fica evidenciado que a ênfase não se dá nos conteúdos escolares, tidos como vinculados à formação taylorista/fordista. O currículo flexibilizado, como o próprio mundo do trabalho, deve enfatizar as subjetividades e a interdisciplinaridade, além de uma aproximação das propostas transdisciplinares, de renovação da construção de conceitos e transformação nas maneiras de pensar (Nicolescu, 1999).

\section{Novos perfis de qualificação}

A primeira característica marcante do novo perfil do trabalhador é a necessidade de que este seja o gerenciador de seu próprio trabalho. A nova gerência flexibilizada propõe relações hierárquicas menos rígidas e verticalizadas, o que os empresários denominam de "baixo grau de hierarquização".

Outra característica é o desenvolvimento das competências sócio-comunicativas. $\mathrm{O}$ trabalhador deve ser comunicativo, expressar os problemas ocorridos, liderar equipes, relacionar-se com a gerência e 
com outros setores da produção, resolver problemas técnicos e administrativos etc., o que lhe exige capacidade de articulação comunicativa para realizar a contento estas multitarefas na empresa.

Além disso, as máquinas eletroeletrônicas exigem menos manipulação e mais interação abstrata, cognitiva, para, inclusive, prever e sanar erros de operação do sistema, o que também exige experiência, conhecimento tácito (Kuenzer, 2003). Do trabalhador, enfim, exigese o conhecimento profundo do processo de produção, com vistas a prever os possíveis erros da operação:

A exigência dessas novas competências seguramente implicará em que as instituições formadoras busquem alternativas técnico-pedagógicas para que as habilidades necessárias sejam adquiridas pelo operário durante o processo de formação. Dentro dessa lógica, tornam-se importantes o desenvolvimento da capacidade de adquirir e operar intelectualmente novas informações e a competência de superar hábitos tradicionais adquiridos numa forma ultrapassada de relações sociais, baseada na oposição linear entre capital e trabalho. (CNI, 1993, p. 18)

Este modelo de formação é orgânico aos novos tempos de crise do capitalismo, em que o desemprego estrutural avassala as possibilidades de que os trabalhadores formados consigam seu "lugar ao sol" no mercado de trabalho. Ideologicamente, este movimento ocorre pela responsabilização individual do trabalhador, de seus anseios e expectativas.

A formação profissional não pode mais estar focada na estrita formação para um cargo ou função, mas, ao contrário, esta deve ser mais ampla, voltada para o "ensinar a pensar", cabendo ao professor (ou instrutor) ajudar o educando-trabalhador a aprender, não mais como o "velho" professor que ensina, mas o educador que é instrumento de "repassagem e aquisição do conhecimento" (idem, ibid., p. 19). O professor é concebido como o "facilitador da aprendizagem" (idem).

As três habilidades e o PLANFOR

O documento EBFP considera que são três os conjuntos de habilidades demandadas aos trabalhadores, segundo o perfil de eficiência para a produtividade da indústria brasileira e a consequente competitividade no mercado nacional e internacional: habilidades básicas, 
habilidades específicas e habilidades de gestão. Estas passaram a ser o norte a ser seguido na política de formação profissional no país, no governo de FHC: o Plano Nacional de Qualificação do Trabalhador (PLANFOR).

Este projeto, que vigorou de 1996 a 2003, teve como objetivo explícito a democratização ao acesso à formação profissional para os trabalhadores (Brasil, 1999). Sua base formativa são as três habilidades propostas no documento EBFP, reproduzidas ipsis literis em seu documento orientador, denominado "Educação profissional: um projeto para o desenvolvimento sustentado" (Brasil, 1995).

Há, na adoção das habilidades no PLANFOR, uma relação de esvaziamento e precarização da formação para a classe trabalhadora, no sentido de negar a esta o acesso aos conhecimentos científicos e técnicos mais avançados. Bulhões $(2004$, p. 41) aponta como isso ocorreu nos cursos ministrados no âmbito do Plano, no Rio Grande do Sul: "A qualificação profissional que a maioria dos trabalhadores consegue obter, em sua busca por recursos que facilitem a inserção no mercado de trabalho, caracteriza-se como cursos básicos, de duração variável, sem regulamentação curricular e sem pré-requisito de escolaridade, em geral pagos".

Este tipo de formação de curta duração não é suficiente para a inserção de trabalhadores no mercado de trabalho com as características flexíveis e tecnológicas hoje existentes. Kuenzer (2006) afirma que, no período de 1995 a 2001, o investimento no PLANFOR subiu de R \$28 milhões para $\mathrm{R} \$ 493$ milhões, ao mesmo tempo em que a carga horária média dos cursos caiu de 150 horas/aula para 60 horas/aula, restringindo a possibilidade da qualidade dos cursos ofertados. Daí se pode verificar uma distorção desta política "pública" de formação e qualificação profissional. Na verdade, tais cursos representam uma forma subordinada de acesso a uma formação profissional para a maioria da classe trabalhadora. Segundo Bulhões (idem, p. 42):

$\mathrm{O}$ acesso e a qualidade do ensino profissional são, portanto, diferenciados. A fórmula tradicional, no país, constitui-se na oferta de cursos de qualificação de duração variável, centrados exclusivamente no treinamento específico, que não contribuem para a elevação do nível de escolaridade dos trabalhadores (Salm; Fogaça, 1998, p. 6). Essa formação, além de defasada em relação às novas exigências referidas, é fornecida majoritariamente por instituições privadas, como foi visto. 
Um dos objetivos do PLANFOr foi, através de uma qualificação maciça da mão-de-obra, garantir para a população mais carente condições de empregabilidade (também exposta no documento EBFP). No entanto, apenas ao se apontar que foi justamente no governo de FHC que se colocou em marcha uma reforma trabalhista, que visou restringir direitos trabalhistas e implementar formas de trabalho precarizadas, como a terceirização, o trabalho por tempo determinado etc., percebe-se que é contraditória a ação governamental.

Como assinala Cêa (2006), o PLANFOr não pode ser desvinculado da ação neoliberal do Estado brasileiro sob o governo de FHC. O Plano, utilizando-se de um fundo público, o FAT, beneficiou um enorme mercado privado de formação profissional. Da mesma forma, estes recursos, na ordem de 2,7 bilhões no período de 1995 a 2001, foram investidos em cursos na maioria sem a qualidade necessária para a verdadeira inserção dos trabalhadores, revelando a faceta de exclusão do neoliberalismo, travestida, neste caso, de um esforço público de qualificação dos mesmos.

Kuenzer (2006, p. 887) ainda lembra que o Decreto n. 2.208/ 97, que forneceu o suporte jurídico ao PLANFOR, é derivado de um acordo entre o MEC e o Banco Mundial e visou à separação entre o ensino médio e a educação profissional, num retrocesso que lembrou a histórica dualidade estrutural na educação brasileira.

Para além dos interesses analíticos da aproximação do PLANFOR com a implementação do neoliberalismo no Brasil, o que se considera aqui como um fato, pretende-se articular esta política de formação neoliberal com as três habilidades presentes no documento Educação Básica e Formação Profissional (CNI, 1993). Esta articulação pode ser feita, segundo defende-se aqui, por meio do esvaziamento, na prática, da formação profissional, que, ao invés de se basear em conteúdos científicos densos aliados à prática laboral, passa a se basear em habilidades genéricas, muito mais centradas em comportamentos flexibilizados dos trabalhadores do que em conhecimentos.

Esta discussão, no âmbito da educação básica, foi feita por Duarte (2000) a respeito dos valores do "aprender a aprender", que é fundamental na composição da noção de "empregabilidade polivalente e a longo prazo" (CNI, 1993, p. 21), proposta no documento aqui analisado. Silva (2007), ao discutir as competências e o currículo na reforma 
dos anos de 1990, afirma a aproximação das políticas com estes pilares do "aprender a aprender" derivados da Conferência Mundial de Educação para Todos, de Jontiem, em 1990, e também afirmados no Relatório Jacques Delors, de 1996. Para a autora:

A finalidade de uma educação que se volta para o "aprender a fazer" possui como referência a noção de competências e vincula a educação diretamente às razões do mercado de trabalho. Assim, toda a educação básica deveria ter como um de seus pilares o aprender a fazer, que, mesmo sendo indissociável do aprender a conhecer, "está mais estreitamente ligada à questão da formação profissional: como ensinar o aluno a pôr em prática os seus conhecimentos e, também, como adaptar a educação ao trabalho futuro quando não se pode prever qual será a sua evolução" (Delors, 2000, p 93). (Silva, 2007, p. 114)

É justamente sobre a incerteza do mundo do trabalho futuro (e presente) que se assenta a formação proposta no PLANFOR e derivada das proposições dos empresários. A estas incertezas soma-se a individualização das qualidades requeridas dos trabalhadores (qualidades subjetivas, definidas pelo saber-ser). A seguir, será analisada cada uma das três habilidades acima mencionadas.

\section{Habilidades básicas}

O objetivo das habilidades básicas é "ensinar a pensar": "Aprender a pensar significa, entre outras coisas, aprender a identificar e superar alguns erros típicos do pensamento, aparentemente universais (...)" (CNI, 1993, p. 20). São estes os erros de pensamento: visão estreita, parcialismo, egocentrismo, arrogância, polarização e apego ao juízo inicial. O trabalhador, portanto, deve ser aberto ao novo, flexível para se adequar às diversas situações; deve, portanto, ter uma visão ampla da produção e do mundo, ser imparcial, ou seja, não entender o mundo e a sociedade por um viés antigo, por exemplo, da constituição da sociedade como polarização entre capital e trabalho. Também o trabalhador deve sair de si e lidar com os outros; não ser egocêntrico, no caso, significa a necessidade de olhar o outro, reconhecer o outro como sujeito e, em uma atitude de flexibilidade relacional, trabalhar com equipes, se relacionar, ouvir o outro e agir de forma competente, como um verdadeiro líder. Eis o perfil a ser formado desde a educação básica. 
No âmbito do PLANFOR, as habilidades básicas foram assim consideradas: competências e conhecimentos gerais, como comunicação verbal e escrita, leitura e compreensão de textos, raciocínio, saúde e segurança no trabalho, preservação ambiental, direitos humanos, informação e orientação profissional, entre outras (Bulhōes, 2004).

\section{Habilidades específicas}

Nestas, o principal conceito é o de "empregabilidade polivalente e a longo prazo" (CNI, 1993, p. 21), que significa a necessidade de que sejam disponibilizados cursos de qualificação profissional e de requalificação, para atualização e para os que ficaram sem emprego. O objetivo é que todos os trabalhadores da PEA possam estar disponíveis e qualificados para serem, a qualquer momento, chamados ao mercado de trabalho. Para os que estão empregados, é necessário que se qualifiquem constantemente, para que possam acompanhar as mudanças e as necessidades da empresa de constante melhora nos sistemas produtivos (Ferretti, 2003).

No PLANFOR, foram consideradas habilidades específicas: competências e conhecimentos relativos a processos, métodos, técnicas, normas, regulamentaçôes, materiais, equipamentos e outros conteúdos específicos das ocupações (Bulhões, 2004).

\section{Habilidades de gestão}

Uma nova visão advinda do sistema de produção pós-fordista/ taylorista exige do trabalhador capacidade de gerir seu próprio trabalho, o tempo e relacionamentos dentro da empresa. Neste cenário flexibilizado, afirmam os empresários: "O próprio conceito de 'gerenciar' também muda, pois se desloca do espaço privilegiado do 'posto de mando' e passa a ser requisito de todos os níveis da produçáo e da prestação de serviços" (CNI, 1993, p. 21).

As habilidades de gestão encontram-se no âmbito do que insistentemente os empresários tentam denominar como o fim da luta de classes, da rivalidade entre capital e trabalho. $\mathrm{Na}$ empresa moderna, o trabalhador, mais que obedecer a ordens, deve ele mesmo se gerenciar, gerenciar seu trabalho, seu comportamento, enfim, deve por si tomar decisōes pertinentes à empresa, de modo que seu envolvimento seja 
mais denso e comprometido com os rumos desta. Daí o "aprender a ser” presente nos quatro pilares da educação e subordinado ao aprender a ser um trabalhador autônomo tanto na empresa, como já foi citado, quanto fora dela, ao aprender a gerenciar a própria carreira e as condições da própria empregabilidade.

No PLANFOR, foram definidas como habilidades de gestão: competências e conhecimentos relativos a atividades de gestão, autogestão, melhoria da qualidade e da produtividade de micro e pequenos estabelecimentos, do trabalho autônomo ou do próprio trabalhador individual, no processo produtivo (Bulhões, 2004).

A ênfase nas três habilidades, como horizonte formativo do PLANFOR, não é contrária aos interesses dos empresários na formação da mão-de-obra para uma indústria competitiva. Desse modo, estas habilidades, que são necessidades de uma determinada classe social - a burguesia industrial -, foram generalizadas como sendo o objetivo de formação de toda a classe trabalhadora. Tanto é assim que o discurso da empregabilidade e do empreendedorismo, gestado no documento Educação Básica e Formação Profissional, adotado no PLANFOR e presente nas políticas da educação básica nos anos de 1990, encontra-se ainda no senso comum, nas políticas educacionais calcadas no "aprender a aprender" (Duarte, 2000; Silva, 2007) e reproduzidas nos documentos mais atuais dos empresários reunidos na Confederação Nacional da Indústria (CNI, 2007).

A seguir, será analisado o último tópico do documento Educação Básica e Formação Profissional (CNI, 1993), relativo à participação dos empresários nos rumos da educação brasileira.

\section{Participação dos empresários}

O tópico final do documento EBFP trata da participação dos empresários no sistema educacional e, em resumo, o que se pretende é que haja uma articulação entre estes e os entes públicos na oferta e gerenciamento da educação brasileira. $\mathrm{Na}$ verdade, os empresários peticionam a participação ativa nas decisões referentes aos destinos da educação brasileira, incluindo aí participação nas esferas de decisão do Ministério da Educação e até mesmo no cogerenciamento das escolas. 
É importante retomar, para melhor compreensão, que os empresários insistem na crise do sistema educacional brasileiro, dando como solução a mudança gerencial do mesmo, corrompido pela má qualidade e pelo descompasso entre a formação realizada e as demandas sociais (entenda-se as demandas dos empresários para a formação de mãode-obra). Esta mudança gerencial, portanto, aproximaria a gestão do sistema público de educação à gestão das empresas privadas, garantindo, assim, a eficiência e a eficácia necessárias para uma educação voltada para as exigências da competitividade.

Oliveira (2003b) faz uma crítica da participação dos empresários na educação como sintoma da privatização do ensino no país.

Essa preocupação do empresariado em participar diretamente na administração escolar pode também ser vista como mais uma das formas de se buscar a privatização do sistema educacional. Como destacou Gentili (1998), a privatização da educação não tem que seguir a mesma lógica que ocorreu com o conjunto de empresas estatais, quando o Estado passou para a mão da iniciativa privada a oferta de certos serviços como água, telefonia, energia elétrica, transporte etc.

No processo educacional, a privatização pode ocorrer de várias formas, desde a iniciativa privada ofertar diretamente o serviço, como buscar que os próprios indivíduos financiem os seus estudos. De qualquer forma, qualquer uma dessas modalidades de privatização deixa explícita uma diminuição da intervenção estatal no provimento integral desses serviços. Entenda-se bem: provimento integral, o que não implica dizer que o Estado deixe de intervir, visando assegurar ao capital privado maior apropriação de riqueza. (p. 52-53)

No entanto, como já foi afirmado sobre o governo FHC, a atuação dos empresários, na sua prática de pressão sobre o governo federal, em nada justifica pensar que esta classe se vincula, de fato, a um projeto de melhoria da qualidade de vida dos trabalhadores e, consequentemente, da melhoria da educação.

Claro está que o projeto de intervenção dos empresários tende a ser uma forma mais direta de intervir no projeto de educação do país, deslocando os seus objetivos de formação para os objetivos da classe burguesa, em especial através da participação nos fundos públicos. No caso do PLANFOr, por exemplo, a gestão dos recursos do FAT foi feita de forma tripartite, entre governo, empresários e trabalhadores, de certo 
modo atendendo a esta reivindicação da burguesia industrial. Esta participação, assim como a ênfase no financiamento de instituições privadas no âmbito do PLANFOR, demonstra que interesses públicos e privados são articulados no país, mediados pela gerência estatal.

\section{Considerações finais}

A partir das reflexões aqui empreendidas, procurou-se demonstrar a relevância da análise dos documentos e ações sobre a educação produzidos no âmbito das organizações da classe burguesa no Brasil. Foi neste sentido que se pretendeu realizar a análise aprofundada do documento Educação Básica e Formação Profissional, produzido pela CNI, em 1993.

Considera-se este documento como um dos mais importantes tratados da burguesia industrial brasileira sobre a educação, que demonstra como esta classe se refere à política de formação para a classe trabalhadora, relacionando este projeto ao seu propósito de competitividade no interior do cenário do capitalismo contemporâneo.

Em 1993, com o documento EBFP, a CNI mostra para a sociedade e, em especial, para o governo brasileiro o seu projeto educacional tanto para a educação básica, quanto para a educação profissional, sendo, neste campo, protagonista das proposições que, a partir de então, seriam fato comum nas políticas educacionais, tais como a ênfase nas habilidades e competências genéricas e flexíveis. As ações empresariais derivadas das suas proposições para a educação estiveram presentes no principal projeto de educação profissional do governo FHC, o PLANFOR.

Conceitos como a empregabilidade, hoje presente no senso comum educacional e social, já se encontravam no texto da CNI, em 1993. Este conceito, em consonância com a ênfase nas habilidades genéricas a serem exigidas dos trabalhadores, torna-se orgânico ao projeto de sociabilidade neoliberal, baseado em relaçóes individualistas e competitivas, típicas do momento de crise do capitalismo. Esta, por sua vez, não pode aparecer socialmente como uma crise generalizada do sistema capitalista, mas sim como uma situação de responsabilização individual pelo sucesso ou fracasso no trabalho. Esta ideologia de responsabilização individual, fortemente publicizada por diversos meios durante os anos de 1990 e 2000 , tem na educação seu corolário desde a chamada pedagogia das 
competências (Silva, 2007; Ramos, 2001) ou, mais genericamente, pelas "pedagogias do aprender a aprender" (Duarte, 2000).

Esta relação entre as pedagogias que esvaziam a educação dos conteúdos científicos densos e a formação básica e profissional encontra-se, no documento EBFP, na ênfase nas três habilidades: básicas, específicas e de gestão. No entanto, não se pode deixar de lembrar que, ideologicamente, esta proposição da burguesia industrial para a educação vem revestida de um discurso sobre uma educação integral, que une teoria e prática, aproximando-se das proposiçôes mais avançadas da esquerda marxista na educação. Todavia, esta aproximação é apenas aparente, pois as proposiçôes da burguesia industrial para a formação do trabalhador nada mais são que propostas para que os trabalhadores desempenhem, da melhor maneira possível, diversas tarefas na produção. Algo muito diferente é o projeto de educação politécnica proposta pela tradição marxista na educação.

Outro objeto a ser explorado a partir deste é a retomada da teoria do capital humano, presente ainda hoje nos documentos da $\mathrm{CNI}$ (2007), mostrando a densidade das proposições efetivadas no início da década de 1990. Também as discussões sobre a privatização da educação podem ser adensadas pela análise das proposições dos empresários na participação do gerenciamento da educação.

Para finalizar, a análise do documento EBFP mostrou-se importante para alicerçar as reflexôes sobre a educação brasileira nos anos de 1990, a qual, após 1993, passou por um período de muitas mudanças, em especial após a aprovação da Lei de Diretrizes e Bases da Educação Nacional, em 1996, e das leis e decretos posteriores que regulamentaram os vários âmbitos da educação. Este cenário pode ser mais bem entendido a partir da análise das proposições da burguesia industrial para a educação e a sua luta pela hegemonia na sociedade, por meio das propostas e açóes desta classe sobre a sociedade e o governo.

Recebido em janeiro de 2009 e aprovado em setembro de 2009.

\section{Referências}

BRASIL. Ministério do Trabalho e Emprego. Educação profissional: um projeto para o desenvolvimento sustentado. Brasília, DF: SEFOR, 1995. 
Educação básica e formação profissional na visão dos empresários brasileiros

BRASIL. Ministério do Trabalho e Emprego. Reconstituindo a institucionalidade da educação profissional no Brasil. Brasília, DF, 1999.

BULHÕES, M.G.P. Plano Nacional de Qualificação do Trabalhador - PlANFor: acertos, limites e desafios vistos do extremo sul. São Paulo em Perspectiva, São Paulo, v. 18, n. 4, p. 39-49, 2004.

CÊA, G.S.S. Planfor: reforma do Estado e acumulação flexível: tecendo fios invisíveis. Educere et Educare, Cascavel, v. 1, n. 2, p. 229244, jul./dez. 2006.

CONFEDERAÇÃO NACIONAL DA INDÚSTRIA. Competitividade industrial: uma estratégia para o Brasil. Rio de Janeiro: CNI, 1988.

CONFEDERAÇÃO NACIONAL DA INDÚSTRIA. Educação básica e formação profissional: uma visão dos empresários. In: REUNIÃO DE PRESIDENTES DE ORGANIZAÇÕES EMPRESARIAIS IBEROAMERICANAS, 6., 1993, Salvador, BA. Educação básica e formação profissional. Rio de Janeiro: CNI, 1993.

CONFEDERAÇÃO NACIONAL DA INDÚSTRIA. Educação para a nova indústria: uma ação para o desenvolvimento sustentável do Brasil. Brasília, DF: CNI; SESI; SENAI, 2007.

DELUIZ, N. O modelo das competências profissionais no mundo do trabatho e na educação: implicações para o currículo. Disponível em: <http:// www.uepg.br/formped/disciplinas/Estagio\%20Comp.Profissionais.pdf>. Acesso em: 20 dez. 2008.

DELUIZ, N. Formação profissional no Brasil: enfoques e perspectivas. Boletim Técnico do SENAC, Rio de Janeiro, v. 19, n. 1, p. 34-44, 1993.

DUARTE, N. Vigotski e o "aprender a aprender": crítica as apropriaçōes neoliberais e pós-modernas da teoria vigotskiana. Campinas: Autores Associados, 2000.

FERRETTI, C. et al. Escola e fábrica: vozes de trabalhadores em uma indústria de ponta. Cadernos de Pesquisa, São Paulo, n. 118, p. 155188, mar. 2003.

HARVEY, D. Condição pós-moderna: uma pesquisa sobre as origens da mudança cultural. São Paulo: Loyola, 2002. 
KUENZER, A.Z. A pedagogia da fábrica. São Paulo: Cortez; Campinas: Autores Associados, 1985.

KUENZER, A.Z. A reforma do ensino técnico no Brasil e suas consequências. In: Ferretti, C.; Silva Junior, J.R.; Oliveira, M.R.N.S. (Org.). Trabalho, formação e currículo: para onde vai a escola? São Paulo: Xamã, 1999. p. 121-140.

KUENZER, A.Z. Exclusão includente e inclusão excludente: a nova forma de dualidade estrutural que objetiva as novas relações entre educação e trabalho. In: Lombardi, C.; Saviani, D.; Sanfelice, J.L. (Org.). Capitalismo, trabalho e educação. Campinas: Autores Associados, HISTEDBR, 2002. p. 77-96.

KUENZER, A.Z. As relações entre conhecimento tácito e conhecimento científico a partir da base microeletrônica: primeiras aproximações. Educar em Revista, Curitiba, n. especial, p. 43-69, 2003.

KUENZER, A.Z. A educação profissional nos anos 2000: a dimensão subordinada das políticas de inclusão. Educação \& Sociedade, Campinas, v. 27, n. 96, p. 877-910, out. 2006.

LODI, L.H. Avaliação do PLANFOR: uma política pública de educação profissional em debate. São Paulo: unitrabalho, 1999.

OLIVEIRA, E. Toyotismo no Brasil: desencantamento da fábrica, envolvimento e resistência. São Paulo: Expressão Popular, 2004.

OLIVEIRA, R. Empresariado industrial e a educação profissional brasileira. Educação \& Pesquisa, São Paulo, v. 29, n. 2, p 249-263, jul./dez. $2003 a$.

OLIVEIRA, R. O empresariado industrial e a educação brasileira. Revista Brasileira de Educação, Rio de Janeiro, n. 22, p. 47-60, jan./abr. 2003b.

RAMOS, M.N. Pedagogia das competências: autonomia ou adaptação. São Paulo: Cortez, 2001.

RODRIGUES, J. O moderno principe industrial: o pensamento pedagógico da Confederação Nacional da Indústria. Campinas: Autores Associados, 1998. 
SAVIANI, D. A nova lei da educação: LDB, trajetória, limites e perspectivas. Campinas: Autores Associados, 1997.

SILVA, M.R. Curriculo e competências: a formação administrada. São Paulo: Cortez, 2007. 